\title{
At the Crossroads: Future Directions in Trust Research
}

\author{
Reinhard Bachmann
}

University of Surrey

School of Management

Guildford, GU2 7XH

United Kingdom

r.bachmann@surrey.ac.uk

Reinhard Bachmann is Professor of Strategy at the University of Surrey. He has published widely in journals such as Organization Studiers, British Journal of Sociology, Cambridge Journal of Economics, and European Societies. With Christel Lane he edited Trust Within and Between Organizations (Oxford University Press 1998/2000). He is also the editor of the Handbook of Trust Research (Edward Elgar 2006) and the Landmark Papers on Trust (Edward Elgar 2008), both with Akbar Zaheer. In 2011, he founded the Centre for Trust Research (CTR) at Surrey University. 


\title{
At the Crossroads: Future Directions in Trust Research
}

\author{
Abstract: This forum paper is intended to stimulate a debate on a \\ fundamental conceptual issue in trust research. It argues that the \\ dominant stream of literature focuses too much on the micro level of \\ trust building processes and hence promotes a reductionist \\ understanding of the phenomenon. In future trust research, it is \\ suggested to place considerably more emphasis on the 'constitutive' \\ embeddedness of actors' behaviour in the institutional environment. \\ The latter is shown to be conducive to overcoming the limitations of \\ current mainstream trust research and to developing new insights into \\ the role and functioning of trust in modern business systems.
}

Keywords: institutions; institutional-based trust; macro-perspective on trust; trust repair

\section{Introduction}

In the past two decades, management research has put great effort into analysing the nature and functions of trust in business relationships. Meanwhile, a variety of different conceptual approaches exists and we have gained important insights into how intra- and inter-organisational trust does its job. Despite - or perhaps because of - the fact that considerable progress has been made, it is not only agreement and consensus that emerge. Deep-seated differences in how to conceptually approach the phenomenon are also becoming increasingly evident. Many of the issues concerned here are due to different approaches employed by different social science disciplines within organisational trust research (economics, psychology and sociology), but some 
fundamental disagreements also show that we have now arrived at the crossroads where fundamental decisions regarding the directions of future research are to be made if we, as a research community, want to continue deepening our understanding of the role that trust plays in business contexts. This article not only attempts to spell out where we currently stand with our conceptual work but also suggests a reorientation which places a strong emphasis on the institutional conditions of trust development. The latter, we think, is essential for future debates in our field of research.

In order to develop trust research into an analytically rich and practically fruitful direction in the years to come, it is important that we critically discuss and overcome some notions which seriously restrict our chances to gain further insights. For too long, for example, we have been led by simplistic everyday knowledge when assuming that trust cannot be managed and should be seen as a micro-level phenomenon that emerges spontaneously between two individuals who develop sympathy for each other and maintain a harmonious relationship rather than ending up in permanent disputes and suspicion. This may be true for some types of social relationships but when studying business relationships we need to go a step beyond such assumptions and try to understand why individual actors (managers) and collective actors (organisations) tend to freely invest trust in their relationships with business partners in certain socio-economic environments, and refrain from so doing in other business environments (Lane and Bachmann, 1996).

The latter observation is, in fact, one of the main reasons why trust deserves so much attention when it occurs in business relationships. If trust could not be influenced and indeed be deliberately created and shaped, trust research would largely be a waste of time. As the difference between successfully building trust and not 
being able to manage trust can mean all the difference in how firms and even whole nations fare in the globalised economy (Fukuyama, 1995), this is surely a very important issue. A better understanding of how trust-building processes can be effectively supported is urgently needed in order to develop appropriate methods for policy makers to intervene in existing institutional arrangements, and to actively promote the development or repair of trust in financial and other sector organisations as well as those countries which have recently emerged as being close to bankruptcy. As organisational trust scholars we should abandon the belief that trust is a fragile phenomenon which exists only in intimate relationships between two individuals, largely beyond our influence and control. From our point of view, this is essential in order to transcend the limitations of much of the current research on trust.

In the following, we will critically discuss the micro-perspective on trust and its deficits, on the one hand, as well as the research carried out on institutional-based trust and the influences of institutional settings on trust development processes, on the other. These two approaches are the basis for a number of key differences, useful and misleading ones that appear in the debates between trust researchers. As we see institutional influences as a vital element of many trust-based relationships, we will also show how trust development processes work and, specifically, how institutions do their job in this context. We will then reflect on why institutions are so important for trust research, and finish with a conclusion that summarises our argument.

\section{The micro-perspective on trust}

Unhelpfully, it is not only lay beliefs that support a de-contextualised understanding of trust. Substantial parts of the current academic literature also build on the assumption that the development of trust is essentially a micro-level phenomenon, 
based on frequent contacts between individual actors, i.e. trustors and trustees (McAllister, 1995; Ferrin and Dirks, 2003; Dietz and Hartog, 2006; etc.). In this perspective, trust is often described as a dispositional attitude or state of mind (Rousseau et al, 1998) that an individual develops over time in the face of experiences made with another individual (see also Mayer et al's <1995> well-known conceptualisations of trust). This view has been highly influential in trust research and (mis-)led numerous conceptual and empirical studies on inter- and intraorganisational relationships.

When this approach is employed macro-level factors such as institutions are usually not seen as overly important to the development and quality of relationships between two actors (see, e.g., many contributions in the trust-targeting special issues of several management journals in recent years, including Academy of Management Review in 1998 and 2009). In these contributions to trust research, institutions are, at best, seen as external factors that play a very limited role where a relationship, for example between a sales and a purchasing manager, is under consideration. Certainly, they do not appear as a constitutive part of a business relationship.

From here it is not a big step to the idea that institutions are to be conceptually separated altogether from the notion of trust. Institutional arrangements are then understood as an alternative mechanism to manage uncertainty in organisational relationships. Only in the absence of institutional safeguards, it is argued, may trust develop and become significant with regard to the governance of business relationships. Where behavioural control is achieved by means of institutional rules, the argument goes, trust can neither flourish nor is trust necessary (Shapiro, 1987). In other words, it is either trust or institutions which will prevail in a relationship. Contrary to our view, trust and institutions are seen as largely inimical to one another. 
In this context, it is also interesting to see how the trust-and/or-contract debate links in. In the early studies of the socio-legal tradition (e.g. Macaulay, 1963), having tight contracts and trust were viewed as two different options, and strong forms of contracts were suggested to be counterproductive where trust was to be developed. Newer studies, however, revealed a more complex inter-relationship between contracts and trust (e.g. Arrighetti et al., 1997; Costa and Bijlsma-Frankema, 2005). In some business environments, particularly where legal rules are powerful and consistently applied, lengthy and detailed contracts were found to be firmly associated with, and also supportive to, trust-building processes.

On closer inspection, the micro-perspective on trust is adopted by three strands of the literature which all operate on divergent premises. First, there are many OB and HRM scholars who believe that psychological factors are the strongest drivers of human behaviour. This view is represented, for example, by many contributions in Kramer and Tyler (1996). Second, there is a group of researchers, often economists, who follow Rational Choice assumptions and advocate game theoretic modelling. They reduce trust to a completely calculative decision and also tend to focus on relationships between two individuals, without showing much interest in the wider context in which individual decisions are embedded. Coleman (1990), for example, represents this tradition in trust research. Third, some researchers suggest that trust is essentially a moral issue (e.g., Brenkert, 1998). In this perspective it is equally assumed that individuals essentially live in isolation, ultimately having to report only to their own conscience.

What these three approaches have in common is their reductionist premises and notorious disinterest in the environment in which socio-economic relationships are embedded (Granovetter, 1984). From our point of view it is important to 
recognise how often and how deeply trust is embedded in its socio-economic context. Where this is ignored it will often be very difficult, if not impossible, to understand why two individual or collective (i.e. organisational) actors trust one another in certain environments and refrain from so doing where other characteristics of the environment prevail. In order to get to grips with such issues, we suggest a wider view on trust which systematically includes contextual factors, specifically the institutional arrangements which constitute the business environment in which relationships are nested.

\section{Trust and institutions}

We disagree with all three of the micro perspectives identified above, at least where they claim to offer a comprehensive understanding of trust. However, we do acknowledge that there must - besides naivety - be a reason why the individualistic conceptualisation of trust became so influential in management research. Indeed, sometimes, it does seem that the assumption that institutions are not relevant in some specific cases of trust development holds true. Many empirical examples show that in business contexts there is occasionally room for very personal sympathies and related behaviours. Thus, we admit that it may be useful to make a distinction between two different types of trust: trust can, depending on the way it is generated, either appear in the form of interaction-based trust or as institutional-based trust (Bachmann, 2001). In the first case the micro approach may perhaps suffice. The second case, however, is much more important in business relationships and requires a considerably wider view. Especially in the latter settings, trust has a notorious tendency to be a deeply contextualised phenomenon (Granovetter, 1985). Thus, from our point of view, institutional-based trust, i.e. trust that constitutively builds on institutional 
arrangements, deserves a lot more attention than is currently granted by large parts of the trust literature.

The important point here is that advanced socio-economic systems can hardly rely primarily on interaction-based forms of trust. This form of trust is often not really useful in a business relationship as it has disadvantages which can quickly rule it out as the chief coordination mechanism. It requires repeated face-to-face contacts, is usually very time-consuming to generate and thus, often not very efficient. From our perspective, institutional-based trust appears as a vital form of trust, indispensable in most business relationships, especially in the developed complex business systems in which we live in the age of modernity (Giddens, 1990).

Where institutional trust exists, both parties refer to risk-reducing institutional safeguards in their decisions and can develop trust without any prior personal experiences in dealing with one another. Zucker (1986) has in her historical studies of the US-American socio-economic system of the nineteenth and early twentieth centuries very convincingly shown that institutional forms of behavioural coordination and control, such as institutional-based trust, are fundamental if the function of trust in inter-organisational relationships is to be understood. In Zucker's as well as in our view, institutional-based trust is a very important form of trust which is intrinsically linked to the macro-level arrangements of the business system in which it occurs.

Zucker's work is by no means the only existing research contribution on the macro aspects of trust. A number of other scholars' efforts, typically oriented towards sociological theory, follow the same insights (Child and Möllering, 2003; Hagen and Choe, 1998; Bachmann and Inkpen, 2011; the majority of chapters in Lane and Bachmann, 1998; and most articles in the 2001 as well as the forthcoming special 
issue of Organization Studies on trust). The concept of 'system trust' (Giddens, 1990; Luhmann, 1979), which is in essence very similar to the notion of institutional-based trust, is often referred to in this strand of the literature and a number of empirically working scholars have revealed that institutions do exert a very crucial influence on the trust-building process in organisational relationships. From their and our point of view, trust is conceptualised as an 'organising principle' (McEvily et al., 2003) or a 'social mechanism to coordinate expectations and interaction' (Bachmann, 2001) in relationships between individual and/or collective (i.e. organisational) actors, and not simply as an attitude or state of mind of an isolated individual, as the micro approaches suggest. Here, trust is conceptualised as a decision that embedded social actors make in the light of specific institutional arrangements. This means that certain business contexts are seen as conducive to actors building trust in their relationships to business partners, whereas others are suggested to be discouraging the use of trust as a principal coordination mechanism in business relationships.

The institutional perspective on trust, in our view, is still significantly underdeveloped, irrespective of the fact that it appears to be much further leading than the micro perspective on trust, both in terms of theory building and the development of practically relevant management knowledge. The institutional perspective has not been exploited in its explanatory power yet, perhaps not least because it is a difficult task to design systematic empirical research on the basis of this approach. However, this kind of research seems necessary and very urgent as it is essential for the functioning of differentiated modern socio-economic systems. Approaches which only target the micro-level, and call for better mathematical models of risk assessment on the one hand and/or ethical behaviour by individual managers on the other, seem not sufficient to come to terms with the complexity of today's business world. 


\section{How institutions do their job}

Both interaction-based trust and institutional-based trust, from our point of view, are phenomena that manifest themselves in an active decision by one party to rely on another party under conditions of risk. The trustor permits his or her fate to be determined by the trustee and risks that he or she will experience negative outcomes, e.g. injury or loss, if the trustee proves untrustworthy (Sitkin and Pablo, 1992; Currall and Inkpen, 2006; Li, 2007). Despite the fact that attitudes, dispositions, emotions and calculations are so often viewed as the essential substrate of trust in the micro-level oriented literature, they are, in our view, convincingly only conceptualisible as more or less important antecedents of the trustor's decision to either invest trust in a relationship or refrain from so doing.

Through an active 'leap of faith' (Möllering, 2006) a trustor transforms fuzzy uncertainty (where anything must be considered possible regarding the future behaviour of the other party) into a certain risk which a trustor is prepared to accept when deciding to build a relationship on trust (Bachmann, 2001). A trustor makes specific assumptions about the trustee's future behaviour. He or she thus behaves as if the risk that he or she gets betrayed is existent but not very likely. This is how uncertainty, which an actor would be confronted with in the absence of trust, is transformed into the specific risk that a trustor will find acceptable to bear. Trust, as Luhmann (1979) argues, is a very effective mechanism to reduce uncertainty. But at the same time it produces risk, namely the risk that the trustor's assumptions will be disappointed. Although the latter can never be ruled out it is a big advantage if an actor is faced with the risk of misplaced trust, rather than dealing with uncertainty, i.e. 
a situation where anything can happen at any point in time (Bachmann, 2001). Thus, we can say that a potential trustor who decides to actually invest trust in a relationship draws on a simplifying social mechanism, i.e. a 'leap of faith', which allows him or her to align his or her expectations and interactions with those of the trustee.

This analysis may hold for both interaction-based trust and institutional-based trust, but this is also where the commonalities end. Trust in the form of interactionbased trust develops on the basis of personal face-to-face experiences between two individuals without substantial references being made to any institutional arrangements. Institutional-based trust, by contrast, develops in a social relationship that is constitutively embedded in the institutional environment in which this relationship is placed, building on the trustor's favourable assumptions about the trustee's future behaviour vis-à-vis such conditions.

It is worth noting that in some parts of the literature the concept of institutional-based trust denotes trust in institutions (where institutions, like for example the law, is the object of trust). This may be a form of trust for which empirical examples can be found but this is not what we are primarily interested in. Rather, we suggest that the concept of institutional-based trust refers to the phenomenon that individuals or collective (i.e. organisational) actors develop trust in the face of specific institutional arrangements. Here, one might argue that the notion that trust in institutions, which is sometimes also conceptualised as societal trust (Barber, 1983; Fukuyama, 1995, Sztompka, 1999), is often a vital precondition of trust developed between firms and/or managers vis-à-vis powerful and reliable institutions (Child and Möllering, 2003). This may well be so and both forms of trust may even be highly intertwined and difficult to disentangle in many empirical situations. But it is nonetheless trust between actors, whose interactions are 
constitutively embedded in institutional contexts, which theoretically as well as in practical terms deserves our interest. Trust in institutions might, similar to interaction-based trust, be understood as a micro-level phenomenon where isolated individuals' preferences play the decisive role. This is certainly not what we are chiefly concerned with.

In our perspective, the intrinsic link between the level of interaction and the level of institutional arrangements, as well as the interplay between the two levels, are key to understanding the essence of institutional-based trust. The interconnectedness of and the dynamics between these two levels are in fact a distinctive feature of institutional-based trust, differentiating it from interaction-based trust, where the institutional level plays no (significant) role, on the one hand, and trust in institutions, where, interestingly, the way institutions do their job is actually also eclipsed. In our view, institutional-based trust develops in concrete relationships between two actors who not only unavoidably orient their behaviour to the relevant institutional arrangements but also enact and constantly reproduce the meaning, power and legitimacy of the institutional order in which their decisions and actions are embedded (Giddens, 1990; Kroeger, 2011). This is what the concept of embeddedness in fact stands for. It is a two-way process, irrespective of the fact the influences institutions have on a potential trustor's action is the focus of our argument here.

In order to deepen our understanding of how institutions precisely do their job it seems helpful to consider the notion of a third party guarantor, which has been suggested in the context of research on interaction-based trust (Coleman, 1990). Despite our reservations against the wider generalisability of this approach, this particular notion seems useful (and indeed shows how this approach can move ahead to become a more social concept). Here, the argument is that in the case where the 
(potential) trustor and the (potential) trustee do not know each other through direct contacts, a third actor known to and trusted by the first two actors may function as an intermediary and thus play an essential role in the development of trust between the two parties (Coleman, 1990; Shapiro, 1987). The third party guarantor can do this job in that he or she bridges over both parties', i.e. the trustor's and the trustee's, explicit and tacit knowledge domains, allowing the trustor to make judgments on the trustee's likely future behaviour, which would not be possible otherwise.

With regard to institutional-based trust, we would argue that institutions could be reconstructed as being functionally quite similar to a personal third party guarantor as conceptualised in Coleman's perspective (Bachmann and Zaheer, 2008). Different from interaction-based trust drawing on a person as a third party, institutional-based trust builds on impersonal arrangements (Zucker, 1986). Like a personal guarantor in the case of interaction-based trust, institutions help to establish a 'world-in-common', i.e. shared explicit and tacit knowledge between the trustor and the trustee. In these circumstances, an individual or collective actor usually finds good reasons (Bachmann, 2001) to trust the other party because institutional arrangements are, similar to a personal third party guarantor, capable of reducing the risk that a trustee will behave untrustworthily, allowing the trustor to actually make a 'leap of faith' (Möllering, 2006) and invest trust in a relationship.

\section{Why we need to place institutional-based trust so high on our research} agenda

Our plea to place a much stronger emphasis on institutional-based trust in future research is not only anchored in issues of theory building. The other major reason to focus on studying institutional-based trust is more of a practical nature. Institutional 
arrangements are the only realistic access point to repairing trust in private organisations and public bodies such as banks, automobile manufacturers and governments, which have recently let their stakeholders down and caused a tremendous global trust crisis. This crisis, which is far from being over and still calls for appropriate political intervention, was not simply induced by individuals' fraudulent ambitions but by inappropriate collective strategies and systemic effects. Thus we have good reasons to assume that the current crisis will not be tackled by better calculation, deeper emotions or by individuals' pledges to behave more ethically in the future. What is needed is a macro-approach to trust repair which puts suitable institutional arrangements centre-stage. The micro-level oriented understanding of trust seems very limited in its capacity to analyse as well as to overcome the trust crisis that follows from the global financial crisis.

Business people and other social actors may well have trust-based personal, i.e. face-to-face, relationships with other individual actors, for example their specific financial consultants, and yet have no trust in the behaviour of banks and bankers generally. This shows that the micro-perspective and the notion that macrophenomena are only the sum of individual action or individual attitudes (as suggested by Rousseau et al., 1998), are not appropriate to analysing the trust crisis. The issue is not to repair trust in an individual's 'competence, integrity and benevolence' (Mayer et al., 1995). Rather, it is the representatives of unknown groups of experts who we need to trust (again) in modern socio-economic systems (Giddens, 1990). These experts might be nuclear scientists, air traffic controllers, auto mechanics, doctors or indeed bankers and politicians. In differentiated advanced societies we often have no autonomous and fully self-responsible individual expert who we can trust in the way which organisational psychologists or game theorists would like us to. We need to 
trust unknown collectives, which are represented by our individual doctors, financial advisers etc., and therefore we need to have rules and institutions in place to which these expert groups are likely to orient their behaviour. Only the existence of these rules of behaviour can provide good reasons to assume that individual representatives of unknown collectives who operate in this framework will behave in a predictable and trustworthy manner.

Actors may consider whether to trust or not to trust an autonomous and fully self-responsible individual. In the case of representatives of unknown collectives we often simply have to trust. We must be able (again) to trust bankers, politicians, journalists etc. as reliable performers of their professional roles, and we do so only if we see that there are rules and norms in place which channel the behaviours of the collectives to which they belong. To overcome the current trust crisis we need, before anything else, to regain trust in the effectiveness and fairness of unknown collectives' actions which are rooted in appropriate institutional arrangements. This is what makes the behaviour of unknown collectives predictable, at least to such a degree that we are willing to invest trust (again) in the representatives of these unknown collectives ('expert systems', in Giddens' <1990> words).

In a reductionist perspective, in which collective action is essentially reduced to the interaction of individuals, many forms of human behaviour including the trust crisis, let alone the repair processes necessary to re-establish trust, are difficult to understand. In this perspective it is also not explainable why, for example, there are many cases of ethnically motivated wars where involved individuals report that they had good relationships with individuals of the opposite party and yet got convinced that atrocities against the other side, as a collective, are justifiable. It may be called a prejudice if we trust or do not trust 'the bankers', 'the Tutsis', 'the Americans', 'the 
Koreans', etc. when seeing individuals merely as representatives of these unknown collectives. However, such sweeping generalisations do not only influence our behaviour but are highly functional and indeed indispensible with regard to making sense of the social reality in which we live. As we know from sociological theory (Giddens, 1984; Luhmann, 1995), in highly differentiated socio-economic systems actors inevitably need to simplify the world in order to make sense of it. Such simplifications and generalisations may seem irrational from a reductionist perspective, but they are in fact anything but irrational from a macro perspective on collective social behaviour, which includes the institutional arrangements within which decisions to trust or not to trust are made.

Simplifications (as just or unjust they may occasionally seem from an autonomous and self-responsible individual's point of view) are a vital means to reduce complexity and to rebuild institutional-based trust. These generalisations are grounded in social actors' judgments on factors that constitute the environment in which actors make their decisions, the latter being precisely the reason why it matters so much what these environments look like and what rules are incorporated in the relevant institutional arrangements. In today's world (of business) we have limited face-to-face contact with autonomous and fully self-responsible individuals and thus, in many situations, simply need to rely on unknown collectives of experts, i.e. representatives of the latter. This makes institutional-based trust a vital resource with regard to coordinating and governing the complex socio-economic world that we inhabit. In the current trust crisis we need to re-establish trust in the representatives of unknown collectives such as 'the bankers' or 'the politicians'. This can only be achieved by creating an institutional environment which reliably channels the 
behaviours of those expert groups which are so essential for the functioning of contemporary societies.

\section{Conclusion}

In this paper we have tried to show that the micro approach to analysing trust in business relationships has considerable limitations. In fact we suggest placing much more emphasis on institutional-based trust in our future research. In many relationships between individual and/or collective (i.e. organisational) actors, it is very important to consider the institutional context in which relationships are often deeply embedded. These contexts shape the way that actors make their decisions, including the decision to either trust or not to trust another actor. In certain environments potential trustors may find the inherent risk of trust low enough to invest trust in a relationship with a business partner, whereas trustors may well refrain from trusting a business partner if the environment appears to produce few or no incentives for a potential trustee to behave trustworthily.

Policies to encourage business partners to invest more trust in their relationships can only use one effective access point: the institutional arrangements that characterise the business systems in which business partners meet. Human beings are what they are, with all their dispositions, attitudes, emotions, tendencies to calculative, greedy or fraudulent decision-making. There is no reason to assume that they will change their fundamental nature for no strong reason in the short term. However, what can be swiftly and actively created or changed is the institutional environment which channels the behaviours of actors into certain directions. If, for example, a consistent legal system or a reliable system of education are put in place where these did not previously exist, this can well increase the overall level of trust in 
a specific business system and encourage potential collaborators to trust each other as representatives of a collective whose behaviour is determined by social roles which this collective attributes to them.

Institutions can encourage and discourage certain behaviours while this is often not achieved through individuals' moral ambitions or calculative considerations. Actors simply need good reasons to assume that the risk they accept to run when deciding to invest trust in a relationship is bearable. That is all it takes to channel potential trustors' behaviour, i.e. to make potential trustors more or less inclined to trust representatives of unknown collectives such as supplier organisations, bankers, CEOs of large firms or indeed politicians. In our view, the key to stimulating or repairing trust is to employ suitable institutional arrangements, i.e. to produce or restore institutional-based trust. To gain deeper insights into institutional-based trust (building processes) is thus one of the most important issues on the trust research agenda.

\section{References}

Arrighetti, A., Bachmann, R. and Deakin, S. 1997. Contract Law, Social Norms and Inter-firm Cooperation. In: Cambridge Journal of Economics 21:171-195.

Bachmann, R. 2001. Trust, Power and Control in Trans-Organizational Relations. In: Organization Studies 22, 2:341-369.

Bachmann, R. and Inkpen, A. 2011. Understanding Institutional-based Trust Building Processes in Inter-organizational Relationships. In: Organization Studies 32,2: $281-301$ 
Bachmann, R. and Zaheer, A. 2008. Trust in Interorganizational Relations. In: S. Cropper, M. Ebers, C. Huxham and P. Smith Ring (eds.), Oxford Handbook of Inter-Organizational Relations. Oxford: Oxford University Press, 533-554.

Barber, B. 1983. The Logic and Limits of Trust. New Brunswick: Rutgers University Press.

Barney, J.B. and Hansen, M.H. 1994. Trustworthiness as a Source of Competitive Advantage. In: Strategic Management Journal 15: 175-190.

Bijlsma-Frankema, K. and Costa, A.C. 2005. Understanding the Trust-ControlNexus. In: International Sociology 20, 3: 259-282.

Brenkert, G. 1998. Trust, Morality and International Business. In: C. Lane and R. Bachmann (eds.), Trust Within and Between Organizations. Conceptual Issues and Empirical Applications. Oxford: Oxford University Press, 273297.

Child, J. and Möllering, G. 2003. Contextual Confidence and Active Trust Development in the Chinese Business Environment. Organization Science 14: $69-80$.

Coleman, J.S. 1990. Foundations of Social Theory. Cambridge: MA: Harvard University Press.

Currall, S.C. and Inkpen, A.C. 2006. On the Complexity of Organizational Trust: a Multi-level Co-evolutionary Perspective and Guidelines for Future Research. In: R. Bachmann and A. Zaheer (eds.), Handbook of Trust Research. Cheltenham: Elgar, 235-246.

Dietz, G. and Hartog, D. 2006. Measuring Trust Inside Organisations. Personnel Review 35: 557-588. 
Ferrin, D.L. and Dirks, K.T. 2003. The Use of Rewards to Increase and Decrease Trust: Mediating Processes and Differential Effects. Organization Science 14: $18-31$

Fukuyama, F. 1995. Trust: The Social Virtues and the Creation of Prosperity. London: Hamish Hamilton.

Giddens, A. 1984. The Constitution of Society. Outline of the Theory of Structuration. Cambridge: Polity Press.

Giddens, A. 1990. The Consequences of Modernity. Stanford: Stanford University Press.

Granovetter, M. 1985. Economic Action and Social Structure: The Problem of Embeddedness. In: American Journal of Sociology 91: 481-510.

Hagen, J.M. and Choe, S. 1998. Trust in Japanese Interfirm Relations: Institutional Sanctions Matter. In: Academy of Management Review 23: 589-600.

Kramer, R.M. and Tyler, T.R. 1996. Trust in Organizations. Frontiers of Theory and Research. Thousand Oaks: Sage.

Kroeger, F. 2011. The Institutionalisation of Trust in Interorganisational Economic Relationships. PhD thesis. University of Cambridge.

Lane, C. and Bachmann, R. 1996. The Social Constitution of Trust: Supplier Relations in Britain and Germany. Organization Studies 17: 365-395.

Li P. 2007. Toward an Interdisciplinary Conceptualization of Trust: a Typological Approach. Management and Organization Review 3: 421-445.

Luhmann, N. 1979. Trust and Power. Chichester: Wiley.

Luhmann, N. 1995. Social Systems, Stanford: Stanford University Press.

Macaulay, S. 1963. Non-contractual Relations in Business: a Preliminary Study. In: American Sociological Review 45: 55-69. 
Mayer, R.C., Davis, J.H. and Schoorman, D.F. 1995. An Integrative Model of Organisational Trust. In: Academy of Management Review 20: 709-734.

McAllister, D.J. 1995. Affect- and Cognition-based Trust as Foundations for Interpersonal Cooperation in Organizations. Academy of Management Journal 38: 24-59.

McEvily, B., Perrone, V., and Zaheer, A. 2003. Trust as an Organizing Principle. Organization Science 14: 91-103.

Misztal, B.A. 1996. Trust in Modern Societies. Cambridge: Polity Press.

Möllering, G. 2006. Trust: Reason, Routine, Reflexivity. Amsterdam: Elsevier.

Rousseau, D.M., Sitkin, S.B., Burt, R., and Camerer, C. 1998. Not so Different After all: a Cross-disciplinary View of Trust. In: Academy of Management Review 23: $1-12$.

Shapiro, S.P. 1987. The Social Control of Impersonal Trust. In: American Journal of Sociology 93: 623-658.

Sitkin, S.B. and Pablo, A.L. 1992. Reconceptualizing the Determinants of Risk Behavior. In: Academy of Management Review 17: 9-38.

Sztompka, P. 1999. Trust: A Sociological Theory. Cambridge: Cambridge University Press.

Zucker, L. G. 1986. Production of trust: Institutional Sources of Economic Structure, 1840-1920. In B.M. Staw and L. L. Cummings (eds.), Research in Organizational Behavior 8. Greenwich, CT: JAI Press, 53-111. 